\title{
Comprehensive Identification of Bacteria in Processed Fresh Edible Sea Urchin Using 16S Ribosomal DNA Sequence Analysis: The Products Contain Various Food Poisoning-related Bacteria and Opportunistic Bacterial Pathogens
}

\author{
Teruo Kajikazawa, ${ }^{a}$ Takashi Sugita, ${ }^{b}$ and Akemi Nishikawa*,a \\ ${ }^{a}$ Department of Immunobiology, and ${ }^{b}$ Department of Microbiology, Meiji Pharmaceutical University, 2-522-1 Noshio, Kiyose, Tokyo \\ 204-8588, Japan
}

(Received August 12, 2007; Accepted August 22, 2007; Published online September 19, 2007)

The bacteria contained in processed fresh edible sea urchin (uni in Japanese) were identified with high accuracy using $16 \mathrm{~S}$ ribosornal DNA (rDNA) sequence analysis. The 586 isolates that were recovered from ten domestic products comprised 13 genera and 18 species. The food poisoning-related bacteria Bacillus cereus (B. cereus), Bacillus weihenstephanensis (B. weihenstephanensis), and Staphylococcus aureus (S. aureus) were detected in 4/10 samples, while the causative agents of bacterial opportunistic infections, Staphylococcus equorum (S. equorum), Stenotrophomonas maltophilia (S. maltophilia), Burkholderia cepacia (B. cepacia), and Serratia proteamaculans (S. proteamaculans), were detected in all 10 samples. It is not known whether these pathogens were components of the sea urchin microflora or were the result of contamination from the environment or human contact during the manufacturing process. Nevertheless, strict quality control standards are needed for the processing of fresh edible sea urchin. This is the first comprehensive analysis of the bacterial microflora of processed fresh edible sea urchin.

Key words — processed fresh edible sea urchin, pathogenic bacteria, $16 \mathrm{~S}$ ribosomal DNA, identification

\section{INTRODUCTION}

Food poisoning or decomposition often affects fresh edible seafood as a result of contamination or colonization with microorganisms. The Food San- itation Law (Shokuhin-eisei-hou in Japanese) has been revised based on numerous cases of food poisoning, and microbiological standards have been established for each product. ${ }^{1)}$ In addition, beginning in 2002, an expiration date must be shown on all products. ${ }^{2)}$ However, for processed fresh edible sea urchin (uni in Japanese), only specifications for Vibrio parahaemolyticus (V. parahaemolyticus) have been established. ${ }^{1)}$ Accordingly, the Tokyo Metropolitan Government provisionally established microbiological specifications for general viable bacteria, coliform bacteria, Staphylococcus aureus (S. aureus), and Salmonella species. ${ }^{3)}$ Previously, we examined 126 processed fresh edible sea urchins obtained from a market and examined the relationship between the expiration date set by the manufacturers or importers and the counts of viable bacteria based on this standard. ${ }^{4)}$ Approximately $30 \%$ of the products did not meet the microbiological standards during the period preceding their expiration dates. Since fresh edible sea urchin cannot be sterilized during the manufacturing process, it is possible for various bacteria, constituting the microflora of sea urchins or contaminants from the environment or human contact during the manufacturing process, to colonize these products. The ability to identify bacterial species would provide valuable information on microbiological contamination for both the manufacturer and importer.

The present study is the first to identify in a comprehensive manner, using $16 \mathrm{~S}$ ribosornal DNA (rDNA) sequence analysis, the bacteria contained in processed fresh edible sea urchin.

\footnotetext{
${ }^{*}$ To whom correspondence should be addressed: Department of Immunobiology, Meiji Pharmaceutical University, 2-522-1 Noshio, Kiyose, Tokyo 204-8588, Japan. Tel.: +81-424-958740; Fax: +81-424-95-8740; E-mail: nishi@my-pharm.ac.jp
} 


\section{MATERIALS AND METHODS}

Sample Collection — Ten processed fresh edible sea urchins were obtained from a distributor in the Tokyo Metropolitan Central Wholesale Market (Tsukiji Market) in April 2007, including six samples from Hokkaido and four from Aomori.

Viable Bacterial Cell Counts — The numbers of general viable bacteria were counted using the standard determination assay for viable cell counts on a plate $^{5)}$ on the day of collection.

Identification of Bacteria Using 16S rDNA Sequence Analysis — At least 50 colonies per gram of sample were selected randomly from the plate when the numbers of general viable bacteria were counted. For DNA extraction, a few cells were suspended in $100 \mu \mathrm{l}$ of physiological saline then incubated at $100^{\circ} \mathrm{C}$ for $15 \mathrm{~min}$. Then, $3 \mu \mathrm{l}$ of the heated cell suspension was added as DNA template to $27 \mu \mathrm{l}$ of a PCR mixture that consisted of Ex Taq polymerase (Takara, Shiga, Japan) and the 27F (5'-AGAGTTTGATCCTGGCTCAG-3') and 1492R (5'-GGTTACCTTGTTACGACTT-3') primers. The composition of the PCR mixture was as recommended by the manufacturer. PCR was performed with an initial denaturation step at $94^{\circ} \mathrm{C}$ for $1 \mathrm{~min}$, followed by 30 cycles at $94^{\circ} \mathrm{C}$ for $30 \mathrm{~s}$, at $47^{\circ} \mathrm{C}$ for $30 \mathrm{~s}$, and at $72^{\circ} \mathrm{C}$ for $1.5 \mathrm{~min}$, then a final extension at $72^{\circ} \mathrm{C}$ for $10 \mathrm{~min}$. The PCR products were sequenced using the primers 27F, 520F (5'-GTGCCAGCAGCCGCGG$\left.3^{\prime}\right), \quad 1100 \mathrm{~F}$ (5'-GCAACGAGCGCAACCC-3'), 520R (5'-ACCGCGGCTGCTGGC-3'), 920R (5'-GTCAATTCCTTTGAGTTT-3'), and 1492R, using an ABI 310 DNA sequencer and the ABI PRISM BigDye Terminator Cycle Sequencing kit version 3.1 (Perkin-Elmer Applied Biosystems, Foster City, CA, U.S.A.) according to the manufacturer's instructions. Strains with 99\% $16 \mathrm{~S}$ rDNA sequence similarity were defined as conspecific. $\left.{ }^{6}\right)$ The sequence data were analyzed using the National Center for Biotechnology Information (NCBI; Bethesda, MD, U.S.A.) BLAST system (http://www.ncbi.nlm.nih.gov/BLAST/).

\section{RESULTS AND DISCUSSION}

Between 1000 and 7800 colonies of bacteria were recovered per gram of sample from the ten samples. From these, the 16S rDNA sequences of 586 strains were determined, and 268 strains were identified as known bacteria by BLAST searching (Table 1). These strains encompassed 13 genera and 18 species. The $16 \mathrm{~S}$ rDNA sequences of the remaining 318 strains were not linked to known species. Based on the rDNA sequence analyses, five new species belonging to the genera Arthrobacter, Marinomonas, Pseudomonas, and Shewanella were identified. The 16S rDNA nucleotide sequence similarities between the new species and their phylogenetically closest species were less than $97 \%$. Surprisingly, of the ten samples, the food poisoningrelated bacteria Bacillus cereus (B. cereus), Bacillus weihenstephanensis (B. weihenstephanensis), and $S$. aureus were detected in three, two, and one samples, respectively. Sample no. 1 contained both $B$. cereus and $S$. aureus. B. weihenstephanensis, which is considered as a new psychrotolerant species belonging to the B. cereus group, ${ }^{7}$ ) also has the potential to cause food poisoning. ${ }^{8)}$ B. cereus is widely distributed in the environment and causes two types of food poisoning, the emetic and diarrheal syndromes, as well as a variety of local and systemic infections. ${ }^{9)}$ S. aureus is a leading cause of gastroenteritis resulting from the consumption of contaminated food. Staphylococcal food poisoning results from the absorption of staphylococcal enterotoxins that have been preformed in the food. ${ }^{10)} S$. aureus is also a component of the skin microflora in 20 $30 \%$ of healthy individuals. In the present study, in addition to food poisoning-related pathogens, bacterial opportunistic pathogens were detected in all ten samples, including Burkholderia cepacia (B. cepacia), Serratia proteamaculans (S. proteamaculans), Staphylococcus equorum (S. equorum), and Stenotrophomonas maltophilia (S. maltophilia). B. cepacia is capable of causing life-threatening respiratory tract infections in patients with cystic fibrosis, and it can develop multidrug resistance. ${ }^{11)} S$. proteamaculans has been isolated from several samples (blood cultures, tracheal aspirates, and pleural effusion) from a patient with pneumonia. ${ }^{12)}$ S. equorum was originally isolated from a healthy goat; subsequently, isolates have been obtained from the milk of a cow with mastitis, ${ }^{13)}$ and it has also been recovered in clinical specimens in recent years. ${ }^{14)}$ S. maltophilia (formerly Pseudomonas maltophilia) is an opportunistic pathogen that is isolated from various sites, such as the blood, urine, upper airways, wounds, and central venous catheters, ${ }^{15}$ and multidrug resistant strains of this microorganism have been isolated more frequently during the last decade. ${ }^{16)}$ 
Table 1. Identification of Bacteria Recovered from Processed Fresh Edible Sea Urchin by $16 \mathrm{~S}$ rDNA Sequence Analysis

\begin{tabular}{|c|c|c|c|c|c|c|c|c|c|c|c|c|}
\hline \multirow[t]{2}{*}{ Identification } & \multirow{2}{*}{$\begin{array}{c}\text { DNA Data Bank of } \\
\text { Japan accession } \\
\text { number }^{b)}\end{array}$} & \multicolumn{10}{|c|}{ Sample } & \multirow[t]{2}{*}{ Total } \\
\hline & & 1 & 2 & 3 & 4 & 5 & 6 & 7 & 8 & 9 & 10 & \\
\hline Arthrobacter sp. $13^{a)}$ & $\mathrm{AB} 334527$ & & & & & & $1^{c)}$ & & & & & 1 \\
\hline Bacillus cereus & AB334763 & 1 & & & & 5 & & & & & 3 & 9 \\
\hline Bacillus megaterium & AB334764 & 2 & & & 10 & & & & & 12 & & 24 \\
\hline Bacillus weihenstephanensis & AB334765 & & & & & 1 & & 4 & & & & 5 \\
\hline Burkholderia cepacia & AB334766 & & & 2 & & & & 3 & & & & 5 \\
\hline Exiguobacterium undae & AB334767 & 6 & & 1 & & & & & & & & 7 \\
\hline Marinomonas sp. $42^{a)}$ & AB334762 & & & & & & & & & 2 & & 2 \\
\hline Pseudomonas sp. 101 ${ }^{a}$ & AB334526 & 23 & 23 & & 10 & & 40 & & & 24 & 26 & 146 \\
\hline Pseudomonas sp. L18 ${ }^{a}$ & AB334528 & 20 & 5 & 25 & 8 & 24 & 4 & 10 & 47 & 1 & 1 & 145 \\
\hline Pseudomonas veronii & AB334768 & & & & & & & 2 & & 2 & & 4 \\
\hline Psychrobacter glacincola & AB334769 & & & & & & 7 & & 1 & 1 & & 9 \\
\hline Rhodococcus erythropolis & AB334770 & & & & & & & 2 & & & & 2 \\
\hline Serratia proteamaculans & AB334771 & & 20 & & & & & & & & 4 & 24 \\
\hline Shewanella sp. 12a) & AB334772 & & & 1 & 3 & 3 & & & & 9 & 8 & 24 \\
\hline Sphingomonas melonis & AB334774 & & & & & & 2 & & & & & 2 \\
\hline Staphylococcus aureus & AB353073 & 3 & & & & & & & & & & 3 \\
\hline Staphylococcus equorum & AB334773 & 1 & 16 & 21 & 24 & 13 & 12 & 30 & 2 & 31 & 17 & 167 \\
\hline Stenotrophomonas maltophilia & AB353074 & & & 2 & & & & & 5 & & & 7 \\
\hline Total & & 56 & 64 & 52 & 55 & 46 & 66 & 51 & 55 & 82 & 59 & 586 \\
\hline CFU/g at day 0 after collection ${ }^{d)}$ & & 2800 & 1800 & 1500 & 7800 & 1000 & 2000 & 4600 & 3900 & 2000 & 6500 & \\
\hline Expiration date (day) & & 7 & 7 & 11 & 8 & 5 & 7 & 7 & 7 & 4 & 7 & \\
\hline
\end{tabular}

The aim of the present study was not just to detect food poisoning-related or pathogenic bacteria, but also to define in a comprehensive fashion which bacterial pathogens exist in the product. We were very surprised by the number of bacterial species identified. We conducted a similar comprehensive examination of fungi using rDNA sequence analysis and identified 23 yeast species. Of the products examined, $65 \%$ contained opportunistic infectious fungi, including Candida albicans. Opportunistic infections do not occur in healthy individuals. Nevertheless, it is important to note that processed fresh edible sea urchin is contaminated with various pathogenic bacteria and fungi. Although only the most probable number (MPN) of $V$. parahaemolyticus is used as the microbiological specification, as proscribed by the Food Sanitation Law, ${ }^{1)}$ the Tokyo Metropolitan Government has provisionally established microbiological standards. ${ }^{3)}$ Large amounts of microbiological data have been accumulated, from which strict but rational quality control standards should be established, and upon which expiration dates should be based.

In conclusion, the present study is the first to show with high accuracy using 16S rDNA sequence analysis that processed fresh edible sea urchin contains various food poisoning-related and pathogenic bacteria. Our findings should help to improve hygiene standards in the industrial facilities that process sea urchin.

Acknowledgements We thank Ms. Satoko Suzuki and Ms. Junko Shimada for their technical assistance.

\section{REFERENCES}

1) Food Sanitation Law (Shokuhin-eisei-hou in Japanese), Law number 283, (2001, revised).

2) Law concerning the standardization and proper labeling of agricultural and forestry products, Law number 175, (2002, revised).

3) Standard-based collection examination of the Tokyo Metropolitan Wholesale Market Sanitation Inspection Station (1 October 1998).

4) Kajikazawa, T., Sugita, T., Nishikawa, A., Nakajima, F., Ohyama, M., Shoji, N., Kosaka, M. and Wada, Y. (2007) Microbiological Investigation of Fresh Edible Raw Sea Urchin and its Expiration. 
J. Health Sci., 53, 397-400.

5) Guideline for Food Hygienic Examination (Shokuhin-eisei-kensa-shishin in Japanese), (2004) Japan Food Hygiene Association.

6) Stackebrandt, E. and Ebers, E. J. (2006) Taxonomic parameters revisited: tarnished gold standards. $M i$ crobiol. Today, 148-155.

7) Lechner, S., Mayr, R., Francis, K. P., Pruss, B. M., Kaplan, T., Wiessner-Gunkel, E., Stewart, G. S. and Scherer, S. (1998) Bacillus weihenstephanensis sp. nov. is a new psychrotolerant species of the Bacillus cereus group. Int. J. Syst. Bacteriol., 48, 13731782 .

8) Stenfors, L. P., Mayr, R., Scherer, S. and Granum, P. E. (2002) Pathogenic potential of fifty Bacillus weihenstephanensis strains. FEMS Microbiol. Lett., 215, 47-51.

9) Schoeni, J. L. and Wong, A. C. (2005) Bacillus cereus food poisoning and its toxins. J. Food Prot., 68, 636-648.

10) Le Loir, Y., Baron, F. and Gautier, M. (2003) Staphylococcus aureus and food poisoning. Genet. Mol. Res., 2, 63-76.

11) Melo-Coutinho, H. D. (2007) Burkholderia cepacia complex: Virulence characteristics, importance and relationship with cystic fibrosis. Indian J. Med. Sci., 61, 422-429.

12) Bollt, C., Grimont, P., Gainnier, M., Geissler, A., Santy, J. M. and De Micco, P. (1993) Fatal pneumonia due to Serratia proteamaculans subsp. quinovora. J. Clin. Microbiol., 31, 444-445.

13) Meugneir, H., Bes, M., Vernozy-Rozand, C., Mazuy, C., Brun, Y., Freney, J. and Fleurette, J. (1996) Identification and ribotyping of Staphylococcus xylosus and Staphylococcus equorum strains isolated from goat milk and cheese. Int. J. Food Microbiol., 31, 325- 331 .

14) Novakova, D., Sedlacek, I., Pantucek, R., Stetina, V., Svec, P. and Petras, P. (2006) Staphylococcus equorum and Staphylococcus succinus isolated from human clinical specimens. J. Med. Microbiol., 55, 523-528.

15) Looney, W. J. (2005) Role of Stenotrophomonas maltophilia in hospital-acquired infection. $\mathrm{Br} . \mathrm{J}$. Biomed. Sci., 62, 145-154.

16) McGowan, J. E., Jr. (2006) Resistance in nonfermenting gram-negative bacteria: multidrug resistance to the maximum. Am. J. Infect. Control, 34, S29-S37. 